\title{
Diversity, Abundance and Habitat Utilisation of Birds in Periphery of the Mihintale Sanctuary
}

\author{
De Zoysa H.K.S., Sandunika I.A.I., Rathnayake D.G.R.M.M. and \\ Wickramasinghe $\mathrm{S}$.*
}

\author{
Department of Biological Sciences, Faculty of Applied Sciences, \\ Rajarata University of Sri Lanka, Mihinthale, Sri Lanka \\ *sriwick@gmail.com
}

\begin{abstract}
Mihintale sanctuary is one of the important forest reserve located in Sri Lanka with scarce information on avifauna. Although this area has been subjected to anthropogenic activities, periphery areas provide more suitable habitats for different species of birds including migrants. Current study is carried from July 2010 to end of February 2012 in the Faculty of Applied Science premises (disturbed) and remnant grass patch habitats locates adjacent to the Mihintale forest to investigate the abundance species diversity, and habitat utilisation of bird species in two different habitats. Belt transect method $(500 \times 50 \mathrm{~m})$, point counts and the opportunistic observation method were used for data collection. Vegetation analysis were done by using quadrates sampling method and habitat utilisation data were gather by scan sampling method. Shannon-Wiener Diversity Index and Margalef's Diversity Indices were calculated in order to determine the species diversity and richness.

A total of 68 and 99 species belonging to 34 and 42 families were recorded from both disturbed and remnant grass patch nearby Mihintale Sanctuary. Among them $64(94.2 \%)$ breeding residents and $4(5.8 \%)$ winter visitors recorded in disturbed habitat while 87 $(87.8 \%)$ breeding residents and $12(12.2 \%)$ winter visitors recorded in grass patch. In both habitats 7 endemic species were recorded. Out of the total species 45 species from grass patch and 69 species from disturbed area were common.

Shannon Diversity Index $\left(\mathrm{H}^{\prime}\right)$ for disturbed and grass patch habitat were 2.48 and 2.76 respectively. The results indicated that the diversity avifauna significantly $(\mathrm{p}=0.0237)$ higher in the grass patch. Mainly the observed bird species in the study area can be categorized into seven trophic guilds. The majority was insectivores in both habitats (54\% and 41.96\%). 22 and 19 species of plant were predominantly utilised by the birds inhabited the grass patch and in disturbed area respectively. During the breeding period majority of birds utilised all the plant species in grass patch for nesting while disturbed habitat used for collecting nesting materials. Ficus species were recorded as common feeding tree in both habitats. As birds are useful indicator species of the health of an ecosystem they can be used as focal species to gather data on status of habitat and disturbances. This will lead to conservation of birds and their habitats.
\end{abstract}

Keywords: Mihintale Sanctuary, Avifauna, Diversity, Endemic, Conservation, Habitat utilisation 